Best Served Cold: Vengeful Attitudes and Violence among Finnish Adolescents

\author{
C. Cory Lowe \\ corylowe@ufl.edu \\ Department of Sociology and Criminology \& Law \\ University of Florida \\ Noora Ellonen \\ noora.ellonen@tuni.fi \\ School of Social Science and Humanities \\ Tampere University \\ Bryan Lee Miller* \\ BLM2@clemson.edu \\ Department of Sociology, Anthropology and Criminal Justice \\ Clemson University \\ Kirsi Peltonen \\ kirsi.peltonen@tuni.fi \\ School of Social Science and Humanities \\ Tampere University
}

*Corresponding Author

Department of Sociology, Anthropology and Criminal Justice, Clemson University, Clemson, South Carolina 29634, USA

blm2@clemson.edu; Tel (864) 656-3818, Fax (864) 656-1252 


\section{Biographical notes}

C. Cory Lowe, M.A., is a graduate school fellow at the University of Florida where he is pursuing a PhD in criminology in the Department of Sociology and Criminology \& Law. He is also a research scientist at the Loss Prevention Research Council in Gainesville, Florida. His interests include theories of crime and deviance; crime and substance use prevention; research methods; and the role of religious organizations, beliefs, and practices in the etiology and prevention of youth substance use and delinquency.

Noora Ellonen, Dr. Soc. Sci., is a University Lecturer and Senior Researcher in the Faculty of Social Sciences, Tampere University, Finland. She holds a title of docent in Criminology. Her research has focused on child maltreatment and child sexual abuse as well as criminal investigation of crimes against children.

Bryan Lee Miller, Ph.D., is an Associate Professor at Clemson University, recent Fulbright Scholar at Tampere University, President-elect of the Southern Criminal Justice Association, and Chair of the Division of Drug and Alcohol Research Section of the Academy of Criminal Justice Sciences. His research focuses on drugs and society, criminological theory, and criminal justice policy.

Kirsi Peltonen, Dr. Soc. Sci., is a Senior Researcher and University Lecturer at the Faculty of Social Sciences, Department of Psychology, Tampere University, Finland. She holds a title of docent in Mental Health Psychology. Her research has focused on mental health of violence exposed children and adolescents as well as on interventions targeted to them. Especially, she has studied interventions among traumatized children, and trained professionals to use these evidence-based methods. 


\title{
Best Served Cold: Vengeful Attitudes and Violence among Finnish Adolescents
}

\begin{abstract}
Research has identified several predictors of violence; however, few studies have examined the role of revenge as a motivating factor of violent delinquency. In this study, we use multilevel logistic regression models to examine the relationship between beliefs favorable to revenge and violent behavior among a random sample of 6061 adolescents in Finnish schools. The results show that established predictors of violence, such as peer delinquency, unstructured socializing, and violent victimization are all significantly associated with violent behavior. However, attitudes supporting revenge also emerge as a significant predictor of violence even after controlling for other factors. This finding reinforces research suggesting that violence-reduction interventions and initiatives should attempt to promote prosocial means of conflict resolution and reduce beliefs favorable to violence such as support for revenge.

Keywords: violence, youth, revenge, risk-factors
\end{abstract}




\section{Introduction}

Although violence has declined in many Western nations since the 1990s (Farrell, Tilley, and Tseloni 2014), interpersonal violence among youths remains a prevalent social problem and public health concern. In 2017, approximately 24\% of American youths reported participating in a fight in the past year (Child Trends Databank 2018). Alternatively, in 2016, 7\% of youths in Finland reported fighting during the past year (Näsi 2016). Although the prevalence of violence is much lower in Finland, it is still enough to merit concern because violent altercations can lead to injury and even death; however, it may initiate cycles of retaliatory violence (Felson and Eckert 2015). For example, retaliation and revenge play an important role in patterns of gang violence, as gang members seek revenge for harms inflicted by others (Decker 1996).

Furthermore, several criminological theories suggest that revenge may play a much broader role in the etiology of violence. For example, general strain theory, cultural theories of violence, differential association theory, and social learning theory all suggest that a desire for revenge, or beliefs supporting revenge, will promote violence. Unfortunately, few quantitative studies have examined the relationship between vengeful attitudes and violence while controlling for other known predictors of violence (Kivivuori, Savolainen, and Aaltonen 2016).

The lack of quantitative research on the relationship between support for revenge and violence is problematic for a few reasons. First, as McCullough (2008) notes, it is important to understand the role of revenge because it is implicated in so many social problems, including school violence, terrorism, gang wars, and international conflicts. Second, understanding the role of support for revenge is important for theoretical reasons. In fact, the role of beliefs supporting violence is central to the debate between control theorists and social learning/cultural theorists in criminology (Akers 1996; Costello 1997; Hirschi 1996; Matsueda 1997). Some theorists dismiss 
the role of cultural factors and beliefs as a predictor of violence (Kornhauser 1978), while others suggest that variation in attitudes towards violence explain violent behavior.

According to social learning theory, specific beliefs favorable to violence (such as support for revenge) should be a more important predictor of violence than general moral codes that proscribe violence (Akers 2009). However, when studies have examined the relationship between beliefs and violence, measures of support for revenge are typically included in broader, composite measures of beliefs (e.g., Agnew and Huguley 1989; Heimer 1997). Finally, to the extent that research has examined the role of revenge and retaliation in violence, many of these studies have focused on populations within American cities (Jacobs and Wright 2006; Kubrin and Weitzer 2003; Stewart and Simons 2010), the American South (e.g., Copes, Hochstetler, and Forsyth 2013; Lee and Ousey 2011), or have focused on specific types of violence (e.g., intimate partner and gang violence; see Elisha et al. 2010; Matsuda et al. 2013). The current study extends prior research by examining whether support for revenge is associated with physical violence after controlling for other known predictors using novel data from a nationally representative sample of 15- and 16-year-old Finnish adolescents.

\section{Literature Review}

Research suggests that the desire for revenge is a key motivation for committing acts of violence (Jacobs and Wright 2006). Several concepts are often used interchangeably, including retaliation, retribution, and revenge; these concepts are used interchangeably because they all refer to actions in which an individual inflicts pain and suffering upon another in response to some real or perceived harm or affront. Therefore, revenge may take several forms, and these can range from stealing someone else's automobile (Copes 2003), sharing pictures of a former sexual 
partner on the internet (Garman, Sample, and Steele 2019), or committing homicide (Kubrin and Weitzer 2003); in other words, some forms of revenge will involve violence by definition.

However, the range and variety of vengeful acts helps to distinguish it from retribution, which some conceptualize as inflicting harms that are proportional to those of the initial act (Gerber and Jackson 2013). Neither revenge nor retaliation connote that the severity of the response should be proportional to the harms of the initial act and, therefore, can even be spiteful and excessive (Gogineni and Fallon 2013). In this study, revenge is conceptualized in the broadest sense, that is, as private actions that inflict pains upon another in response to the harms (and perceived harms) they have committed, regardless of whether the nature of that response is proportional to the initial harm.

Research indicates that developing a desire for revenge is a common reaction to being wronged. For example, in their study of 513 undergraduate students in a Danish university, Crombag and colleagues (2003) found that 64\% of their sample had felt the "urge to get even" for some wrong committed against them in the past year. Alternatively, in their study of desires for revenge among Kosovar Albanians, Cardozo and colleagues (2000) found that nearly half of the respondents displaced by ethnic cleansing reported experiencing strong desires for revenge. Given the nature and seriousness of ethnic cleansing, some might be surprised that more of the Kosovar Albanians did not desire to avenge the wrongs committed against them. Nevertheless, despite the vast differences in the contexts and experiences of the undergraduates and the Kosovar Albanians, a large portion of both groups experienced a desire to seek revenge. While many people experience a desire for revenge, not everyone acts on that desire; for example, even though Crombag and colleagues (2003) found that $64 \%$ of their respondents experienced the desire to seek revenge, only $29 \%$ of this group acted on that desire and most did 
not resort to violence. A similar proportion of Kosovar Albanians indicated that they would seek revenge if they had the opportunity to do so. Nevertheless, research indicates that revenge is an important factor in many types of violence (Elisha et al. 2010; Jacobs and Wright 2006; Kubrin and Weitzer 2003). For example, in their study of adolescents admitted for assault-related injuries in two emergency departments in urban areas of America, Copeland-Linder and colleagues (2012) found that retaliatory attitudes at admission were significantly associated with subsequent aggression and fighting. Finally, in their study of homicides in St. Louis, Missouri, Kubrin and Weitzer (2003) found that nearly $20 \%$ of all homicides were committed in retaliation.

Revenge is also a common motivation for violence among gang members. As Kubrin and Weitzer (2003) found, the proportion of retaliatory, gang-related homicides was significantly greater than the proportion of gang-related homicides that were non-retaliatory. Decker (1996) suggests that revenge is central to the cycles of violence that occur between rival gangs - after gang members are assaulted, members of the injured gang will retaliate, which may lead to further retaliatory violence. This cycle can go on for years, and violent rivalries may even become part of the gang identity. Interrupting these cycles of violence are key to several gang interventions (Butts et al. 2015).

Revenge may serve many different functions. Some argue that seeking revenge may be a cathartic act; in other words, individuals may derive satisfaction by avenging the harms done to them. This explanation is in accord with general strain theory which suggests that negative interactions (e.g, victimization) produce negative emotions, such as anger and frustration, which creates a need to cope with those emotions (Agnew 2006). Seeking revenge is just one of the means by which an individual may cope, and research indicates that seeking revenge may provide such relief. For example, in their experiment using positron tomography, de Quervain 
and colleagues (2004) found that punishing others for dishonest behavior during an economic exchange activated the reward centers in the brain.

Revenge may also serve other functions. First, exacting revenge may help individuals to maintain their sense of self-worth and their social status (Gogineni and Fallon 2013). Second, seeking revenge for harms may serve as a mechanism of social control; in other words, avenging wrongs serves to maintain social order (Gogineni and Fallon 2013). Specifically, revenge may act as a specific and general deterrent by sending the message that a person will not be victimized or otherwise disrespected without consequences. Both of these functions are central to cultural theories of violence such as the Southern culture of honor (Nisbett and Cohen 1996) and the code of the street (Anderson 2000).

\section{Revenge as a Cultural Adaptation}

The Southern culture of honor hypothesis suggests that, because of historic and economic reasons, revenge is culturally prescribed in the American South. Nisbett and Cohen (1996) argue that the Southern culture of honor developed as part of herding culture among the Scots-Irish in Britain, where herders needed to protect their economic capital (assets) and social capital (status and relationships) in a context where there were few formal sources of social control. When these groups migrated to the United States, they largely migrated to the South and brought their culture with them, and, upon their arrival, these cultural adaptations remained relevant given the structural similarities between their countries of origin and the American South. Presumably, these groups transmitted their beliefs to other groups and to subsequent generations.

This theory has been used to explain the rates of violence that are higher in the American South relative to other regions, and several studies have found that violence may be shaped by this Southern culture of honor (Cohen 1996; Cohen et al. 1996, 1999; Copes et al. 2013; Gastil 
1971; Lee et al. 2007; Lee, Thomas, and Ousey 2009). Unfortunately, except for qualitative ethnographic studies, most of these studies rely on inferring that the culture of violence exists based on differential patterns of violence. In other words, these studies often do not examine whether holding beliefs that support the use of revenge are more prominent among Southerners, nor do they examine whether support for revenge mediates the relationship between Southern identity and violence. However, ethnographic research, such as that conducted by Copes, Hochstetler, and Forsyth (2013) found that adult male bar fighters adhered to a code that resembles the Southern culture of honor. Their respondents noted that they felt the need to defend their honor and the honor of others in response to affronts; they also noted that they engaged in this behavior to deter others from disrespecting them.

Alternatively, Anderson's (2000) code of the street suggests that an oppositional culture has developed in many predominately Black communities. This code of the street is presumed to be a culture adaptation in response to racial segregation, deindustrialization, and concentrated disadvantage that has isolated many predominately Black communities from conventional economic and educational opportunities. This code requires that individuals respond to affronts, with violence for the dual purposes of maintaining social status and deterring others from targeting them. Interestingly, both the Southern culture of honor and code of the street hypotheses suggest that revenge is a cultural adaptation that arises in when institutionalized sources of formal social control are inadequate, ineffective, and/or not trusted. Some have even suggested that oppositional cultures such as the code of the street are the result of Black Americans' exposure to the South's honor culture and cultural transmission (Sowell 2006).

There is support for the link between adherence to the code of the street and violence. 
However, in most of these studies, measures of support for revenge are included as items in composite measures of adherence to the code of the streets. For example, Matsuda and colleagues (2013) examined whether differences in violence between gang members and nongang members was due to their adherence to the code of the street using data from the second evaluation of the National Evaluation of the Gang Resistance Education and Training (GREAT program). They measured adherence to the street code using measures of support for revenge, as well as support for instrumental uses of violence (e.g., deterrence). They found that adherence to the code of the street was central to explaining differences in violence between gang and nongang measures. Other studies have also examined the relationship between adherence to the code of the street and have found that those who show greater support for the code of the street are more likely to engage in violence (Mears et al. 2013; Stewart and Simons 2006, 2010). However, these studies also include support for revenge as items in composite measures of street-code adherence; in other words, they do no specifically examine the relationship between support for revenge and violence.

While Anderson's code of the street was developed to explain violence in predominately Black communities in America, other researchers have examined whether the code of the street influences violence in other areas of the world. For example, in their study of the code of the street among youths in disadvantaged neighborhoods in Germany, Bulgaria, Pakistan, and South Africa, Kurtenbach and colleagues (2019) found that oppositional cultures similar to the code of the street existed in all of these countries. For example, in all of these countries, displays of masculinity through displays of toughness were important to maintaining respect; furthermore, avenging wrongs was a mechanism by which participants believed they could maintain respect and deter others from attempting to harm them. 


\section{Revenge, Social Learning Theory, and Techniques of Neutralization}

Cultural theories such as the Southern culture of honor and the code of the street fall short in explaining how beliefs are socially transmitted and sustained in society. Fortunately, there are micro-level theories which suggest that attitudes and beliefs supporting revenge will be associated with violent behavior. Both differential association and social learning theory suggest that individuals act on the basis of the definitions they hold. Ronald Akers (2009) developed social learning theory as an elaboration of differential association; therefore, many important concepts in the theories are very similar or are the same. Akers conceptualizes definitions as attitudes or rationalizations that form the basis for action, and includes "orientations, rationalizations, definitions of the situation, and other evaluative and moral attitudes that define the commission of an act as right or wrong [or] desirable or undesirable" (Akers and Sellers 2012: 83). According to differential association theory and social learning theory, individuals learn these definitions as they interact with others, and, to the extent that one holds definitions favorable to a particular course of action, they will be more likely to pursue that course of action.

Akers (2009) identifies two types of definitions in his social learning theory - specific definitions and general definitions. General definitions are conceptualized as broad moral codes, such as religious moral codes or the belief that one has a duty to obey the law. Alternatively, specific definitions "orient [a] person to particular acts or series of acts" (Akers 2009:78). As an example, Akers (2009: 78) suggests that one might "believe it is morally wrong to steal and that laws against theft should be obeyed" but "see little wrong with smoking marijuana" and violate prohibitions against marijuana use. For example, an individual might believe that initiating violence is unacceptable, while also believing that it is inappropriate to retreat from an aggressor. Akers further subdivides definitions into positive definitions, negative definitions, and 
neutralizing definitions (Akers and Sellers 2012). Positive definitions are beliefs and attitudes that make a course of action permissible, and neutralizing definitions are those that excuse or justify behaviors that would otherwise be prohibited by conventional standards (Akers 2009). By incorporating neutralizing definitions, Akers subsumes elements of Sykes and Matza's (1957) techniques of neutralization theory which suggests that even though most youths accept conventional standards of behavior, they will adopt techniques of neutralization that allow them to justify or rationalize their deviant behavior. For example, an individual may believe that it is generally impermissible to initiate aggression against another, except when they are responding to affronts and insults (i.e., exacting revenge).

One of the shortcomings of research on social learning theory is that tests of the theory have primarily examined substance use as the outcome (Warr 2002) or composite measures of delinquency (see Pratt et al. 2010). Far fewer tests of social learning theory have examined the relationship between the constructs of social learning theory and violence (Pratt et al. 2010; Warr 2002). When studies have examined the relationship between definitions favorable to violence and violent behavior, they have typically used a composite measure of beliefs that include measures of support for revenge (Agnew and Huguley 1989; Heimer 1997). Unfortunately, like tests of the code of the street hypothesis, these studies do not allow us to understand the specific causal significance of support for revenge.

Furthermore, when studies have examined social learning theory as it applies to violence, they have typically focused on other propositions of social learning and differential association theory, such as the relationship between exposure to violent peers and family members and subsequent violence. Other studies have used measures of general definitions (e.g., belief that it is acceptable to engage in physical fights) rather than specific definitions such as support for 
revenge (Bellair, Roscigno, and Velez 2003; Seddig 2014; Sellers, Cochran, and Winfree Jr 2003). In other words, many of these tests do not examine the relationship between definitions favorable to violence (e.g., support for revenge) and violent behavior.

However, Agnew (1994) examined the relationship between a composite measure of neutralizations and violence using three waves of data from the National Youth Survey. This measure of neutralizations was constructed using four items that captured whether fighting is justified "(1) if the other person started the fight, (2) called you names, (3) did something to make you really mad, or (4) walked all over you" (Agnew 1994:564). Agnew (1994) found that this composite measure of neutralizations, which largely reflects attitudes supporting revenge, was associated with violence in cross-sectional analyses and longitudinal analyses.

Unfortunately, it is unclear whether beliefs supporting revenge are associated with the perpetration of violence after controlling for other factors. This is an important gap in the literature, because there are scholars who argue that variation in beliefs throughout society plays a greater or lesser role in the etiology of delinquency. For example, on one hand there are scholars like Kornhauser (1978), Hirschi (1996), and Costello (1997) who question the proposition that there are codes within society that promote non-conforming behaviors. They take this position because they make the assumption that crime, delinquency, and other antisocial behaviors fulfill desires, and thus require no special motivation (Rebellon and Anskat 2018). As we have explained previously, scholars in the social learning and differential association tradition disagree with this assertion and argue that beliefs may promote violence in society (Akers 1996; Matsueda 1997). Furthermore, according to Akers (2009), specific definitions should be more important in etiological processes than general definitions. Unfortunately, few studies have examined whether specific definitions, such as support for revenge, are associated with violence. 
This study builds on prior research by examining whether support for revenge is associated with an increased probability of engaging in physical violence, while controlling for known predictors of violence. Further, this study makes a novel contribution by examining this relationship among a sample of Finnish adolescents.

\section{Methods}

\section{Data}

The analyses were conducted using data from the 2016 Finnish Self-Report Delinquency (FSRD) Study, which is archived at Finnish Social Science Data Archive (FSD). According to the Finnish National Board on Research Integrity (2019), ethical review is not required for the research using secondary data. The FSRD Study is a series of nationally representative selfreport surveys that focus on juvenile delinquency in Finland and has been conducted eight times since 1995. The 2016 data was collected using a stratified one-stage cluster sample designed by Statistics Finland, and 68 schools were selected with a probability proportional to their size. The 2016 study included 6061 Finnish youths in the ninth grade, which is the final year of mandatory education for students in Finland. Because of this, $74.2 \%$ of students were 15 years old, $24.6 \%$ were 16, and 1.2\% were 17. In Finland, children are assigned to schools according to their municipality. Schools are relatively homogenous and only approximately $9 \%$ of upper schools are privately operated, including vocational schools; however, most private schools are publicly funded and publicly supervised (European Commission, 2017). The data were collected via an online survey, which respondents completed during the school day in the computer lab or in the classroom; the response rate was $79 \%$. 


\section{Measures}

\section{Dependent variable}

The dependent variable in the current study is a dichotomous measure of past-year physical violence. This measure was created using two items. Respondents were asked whether they had participated in a fight in the past 12 months (yes/no) and whether they had beaten up another person in the past 12 months (yes/no). Respondents who affirmatively responded to either of these items were coded as " 1 ," while those who did not were coded as " $0 . "$ Approximately eight percent of the sample reported engaging in either of these types of physical violence in the past year. All descriptive statistics are provided in Table 1.

\section{--- INSERT TABLE 1 HERE ---}

\section{Independent Variables}

Support for Revenge. The measure of support for revenge was created using six items which captured whether youths support the use of violence in response to affronts. Respondents were asked to indicate the extent to which they agreed: (1) it is "important to exact revenge on those who have hurt" them; (2) that they "try to retaliate against anyone who hurts" them; (3) they "get angry" but "also square accounts;" (4) "revenge is morally wrong"; (5) it is "usually better to show mercy than to seek revenge;" (6) it is "always better to not seek revenge." These were Likert-type items and were initially coded such that the response choices ranged from 1 (strongly agree) to 5 (strongly disagree), and 3 was associated with the answer "difficult to say."

\footnotetext{
${ }^{1}$ For option 3, due to the complexities of the Finnish language, the most direct translation to English amounts to "difficult to say," but its meaning in Finnish is intended to be interpreted as "neither agree nor disagree" or "neutral." The scale is intended to be used with this latter interpretation and our main analyses include it this way. Because the language ambiguity of the earlier direct translation of "difficult to say" could be interpreted as "I don't know," additional analyses were conducted with two alternative revenge scales. Response option 3, "difficult to say," was recoded as "missing," and response options 1, 2, 4, and 5 were recoded as 1, 2, 3, and 4, respectively. Since 3 was the modal category for the items (except item 6), this created many missing observations. The two alternative mean scales were created by: (1) using all non-missing observations, and by (2) using only those who answered "Difficult to Say" on no more than 2 of the 6 items (66.7\% complete). The first method resulted in 5,258
} 
However, to create a scale in which higher values correspond to greater support for revenge, items 1,2 , and 3 were reverse coded. The scale was created by calculating the mean for these six items $(\alpha=.83)$.

Lifetime violent victimization. Many studies have found a relationship between victimization and antisocial behaviors such as violence (Jennings, Piquero, and Reingle 2012). Therefore, lifetime violent victimization is included as a control variable. Respondents were asked to indicate whether anyone had ever "physically attacked [them], for example, by hitting, kicking, or using a weapon" (yes/no). Those who had been victimized were coded as "1," while those who had not were coded as " 0 ." Nearly one-third of respondents $(29 \%)$ indicated that they had been violently victimized during their lifetime.

Low self-control. Low self-control is a well-established predictor of violence and other antisocial behaviors (Pratt and Cullen 2000; Vazsonyi, Mikuška, and Kelley 2017). In this study, low self-control is measured using the nine-item standard International Self-Reported Delinquency study (ISRD) self-control scale, which is based on the self-control scale developed by Grasmick, Tittle, Bursik, and Arneklev (1993). The Grasmick et al. (1993) scale is widely used to measure self-control as conceptualized by Gottfredson and Hirschi (1990). In the ISRD self-control scale, youths were asked to indicate whether they agreed with a series of statements. These items captured three of the six dimensions of self-control identified by Grasmick and colleagues (1993), including the extent to which youths are impulsive; prefer exciting, adventurous, and risky activities; and are self-centered/insensitive to others. ${ }^{2}$ These were Likert-

valid observations and the second resulted in 3,991. Multilevel logistic and logistic models with robust standard errors were estimated; although the magnitude of the coefficient for support for revenge was slightly greater in these models $(1.70<O R<1.96 ; .53<\beta<.68)$, there were no substantive changes in the magnitude, significance or directionality of the other parameters.

${ }^{2}$ Youths were asked whether they felt the following statements described them: (1) "I often act on the spur of the moment without stopping to think;" (2) "I often do whatever brings me pleasure in the here and now, even at the cost of some distant goal;" (3) I'm more concerned with what happens to me in the short than in the long run;" 
type items ranging from 1 (strongly disagree) to 4 (strongly agree). The composite measure of low self-control was created by calculating the mean for these nine items $(\alpha=.85)$, and higher scores corresponded to lower self-control.

Parental social control. Research indicates that poor parental supervision and behavioral monitoring are predictors of antisocial behaviors such as violence (Farrington 1998); therefore, parental social control is included as a control. The measure of parental social control was created using four items. Respondents were asked to indicate how often their parents supervised and monitored their children's behaviors. These were Likert-type items ranging from 1 (never) to 5 (always), and included whether the respondents' parents: (1) ask who they are going out with then they go out; (2) know where they are at after school, (3) follow up on their grades, and (4) ensure that they go to bed early. A scale was constructed by calculating the mean for these four items $(\alpha=.72)$; higher scores correspond to greater parental social control.

Unstructured socializing. While parental social control is an important predictor of delinquency and violence, unstructured socializing is also an important predictor of violence (Bernburg and Thorlindsson 2001; Maimon and Browning 2010). On one hand, if a youth is not being supervised by authority figures, they have greater freedom to engage in delinquent behaviors. However, even an unsupervised youth may not engage in delinquent behaviors if they are not participating in activities where they have the opportunity to engage in delinquent behaviors. Therefore, unstructured socializing is included as a control variable. The measure of routine activities was created using three items that captured how respondents use their free time. Respondents were asked to indicate how often they engaged in three types of activities,

(4) "I like to test myself every now and then by doing something a little risky;" (5) "Sometimes I take a risk just for the fun of it;" (6) "Excitement and adventure are more important to me than security;" (7) "I mainly look over my own interests, even if it causes problems to other people;" (8) "If people get upset over something I do, that's their problem, not mine;" (9) "I try to get what I want even when I know that it will cause problems to other people." 
including: (1) hanging out with friends in public places after 9pm; (2) coming home after 10pm on school nights; and (3) going to parties with other youths where there is no adult supervision and most youths are consuming alcohol. These were Likert-type items ranging from 1 (never) to 5 (always) and were averaged to create a scale $(\alpha=.79)$.

Peer delinquency. A large body of research indicates that peers antisocial behaviors are a strong predictor of youth antisocial behavior (Akers 2009; Pratt et al. 2010; Warr 2002). Scholars have offered several explanations for this relationship; for example, Akers (2009) argues that individuals learn to commit antisocial behaviors as they interact with others, while others have suggested that antisocial peers merely provide additional opportunities for antisocial behavior (Warr 2002). Still, others discount the causal relationship between peer conduct and personal conduct altogether, and suggest that (1) antisocial youths merely select into antisocial peer groups, (2) that measures of peer delinquency represent co-offending, or (3) that self-reported measures of peer delinquency are simply a projection of one's own delinquency onto their peers, and are thus a proxy measure of personal delinquency (Gottfredson and Hirschi 1987).

Nevertheless, from a social learning perspective, associating with delinquent peers may lead one to develop general beliefs that undermine respect for the law and thus promote acts such as violence. Therefore, peer delinquency is measured using three self-reported items that capture how many of the respondents' friends have: "fought in a public place," "stolen from a shop or kiosk," or "used marijuana or hashish." Response choices ranged from 1-3, and included "none of them" (1), "one of my friends" (2), and "more than one of my friends" (3). Responses to these items were averaged to create a scale $(\alpha=.80)$.

Demographic controls. Respondents' age, gender, family structure, and immigrant background were included as control variables in the models. Since only Finnish ninth graders 
were included in the sample, the age ranges are restricted. The youths' ages ranged from 15 to 17 , and $74.21 \%$ of respondents were 15 years old, $24.6 \%$ were 16 , and $1.2 \%$ were 17 . Given that a large body of research in the West shows that antisocial behavior increases throughout the teen years (Loeber 2012), age is included as a control variable. Age was dummy coded, and those who were 15 years old are treated as the reference group in the analyses. Regarding gender, boys were coded as " 1 " and girls were coded as " 0 "; $49 \%$ of the sample were boys and $51 \%$ were girls. Family structure was measured as a dichotomous variable. Those who lived with an intact nuclear family (with their biological mothers and fathers) were coded as "0" and those who did not were coded as " 1 ." The latter category included youths who alternated living with their mother and father, those who live in homes with step-parents, single-parent families, and other family structures. Nearly two-thirds $(65 \%)$ of respondents indicated that they belonged to an intact nuclear family. Finally, immigrant background was measured by coding youths who were immigrants, or whose parents were immigrants, as " 1 " and coding those who were not as " 0 ". Approximately $12 \%$ of the respondents or their parents were first-generation immigrants.

\section{Analysis}

The descriptive statistics for all variables, as well as their bivariate correlations, are provided in Table 1. Multilevel logistic regression models were used to examine the relationship between attitudes supporting revenge and violent behavior. These analyses were conducted using Stata 14 and multilevel logistic regression was necessitated by the distribution of the dependent variable and by the study design. On one hand, since the dependent variable - past-year physical violence - is a binary measure, using ordinary least squares regression would be inappropriate as several assumptions would be violated; therefore, logistic regression is appropriate (RabeHesketh and Skrondal 2012). Secondly, respondents are clustered within schools. Multilevel 
models address the nonindependence of respondents in the LSRD by explicitly modeling the heterogeneity that is due to clustering (Rabe-Hesketh and Skrondal 2012).

Analyses were conducted in three steps. First, a null model was estimated to determine whether there was significant variation in past-year violence across schools to merit using multilevel models; although the intraclass correlation (ICC) of the null model was rather small (.034), it did suggest that there was heterogeneity for which traditional logistic models would not account. Second, a multilevel logistic regression model excluding the measure of revenge orientation was estimated to provide a baseline estimate of the parameters. Third, a model including revenge orientation was estimated to determine whether the significance of any of the covariates was affected by its inclusion. To ensure that multicollinearity was not an issue, we estimated single-level OLS regression models and examined the variance inflation factors (VIFs) associated with the predictors (per Allison, 2012). None of the VIFs were concerning (none exceeded 1.49).

The models were estimated with robust standard errors as this is the default for variance estimation in Stata when using sampling weights. This study utilizes the level-2 sample weights included in the FSRD study given that every eligible student within each school was included (i.e., equiprobability is assumed) and schools were sampled with a probability proportional to their size. These are the only weights provided by the study and account for the sampling design and non-response. As Aspouhuov (2006) and Heck, Thomas, and Tabata (2012) note, in this case, incorporating only level-2 weights is not problematic because although the model is multilevel, the sampling design (and weighting) is not; however, they suggest using single-level models as an additional robustness check. Therefore, given this recommendation and the relatively small ICC, standard logistic regression models with cluster robust standard errors were estimated. The 
directionality, magnitude, and significance of support for revenge and the other covariates did not substantively differ from the reported results.

\section{Results}

The results are shown in Table 2. The Akaike Information Criterion (AIC) and Bayesian Information Criterion $(\mathrm{BIC})$ indicate that Model $2(\mathrm{AIC}=2382.84 ; \mathrm{BIC}=2469.54)$ achieved better fit relative to Model $1(\mathrm{AIC}=2492.31$; $\mathrm{BIC}=2572.49)$. Furthermore, since Model 1 is nested in Model 2, a likelihood ratio test was conducted to compare the two. The results indicated that including the measure of support for revenge in Model 2 led to a statistically significant improvement in model fit $\left(\chi^{2}=111.47 ; p<.000\right)$.

Support for revenge was a significant predictor of past-year physical violence in Model 2 $(O R=1.64, R S E=0.01, p<.001) ;$ in other words, for a one-unit increase in support for revenge, the odds of physical violence are expected to increase by a factor of 1.64 . All the other covariates were also significant predictors of past-year physical violence except parental social control (OR $=.91, p=.256)$, family structure $(O R=1.01, p=.926)$, and age. Neither 16-year-olds $(O R=$ $1.22, p=.164)$, nor 17 -year-olds $(O R=.23, p=.083)$ were significantly more likely to engage in physical violence than 15-year-olds. Interestingly, low self-control the only covariate that was a significant predictor of physical violence in Model $1(O R=1.57, R S E=0.23, p<.01)$ but was not a significant predictor in Model $2(O R=1.26, p=.155)$. However, as prior research has found, identifying as a boy $(O R=1.69, R S E=0.24, p<.001)$; lifetime physical victimization $(O R=3.94, R S E=0.54, p<.001) ;$ peer delinquency $(O R=2.17, R S E=0.26, p<.001)$ immigration background $(O R=2.11, R S E=0.42, p<.001)$; and unstructured socializing $(O R=$ $1.60, R S E=0.13, p<.001)$ were all significant predictors of past-year physical violence in

\section{Model 2.}




\section{--- INSERT TABLE 2 HERE ---}

\section{Conclusions, Implications, and Limitations}

Results from this study suggest that support for revenge is a significant correlate of violence even after controlling for other known predictors of violence. These results are in line with prior research which finds that unstructured socializing (Bernburg and Thorlindsson 2001; Maimon and Browning 2010), gender (Ellis, Beaver, and Wright 2009), immigration background (in Nordic countries; Skardhamar, Aaltonen, and Lehti 2014), peer delinquency (Akers 2009; Warr 2002), and other factors are associated with violence. However, neither parental social control, family structure, low self-control, nor age were significant predictors of physical violence. These are all surprising findings given that prior research has found all of these factors to be associated with violence (Farrington and Loeber 1998; Farrington and Welsh 2007; Thornberry et al. 1999; Vazsonyi et al. 2017; Wells and Rankin 1991). The non-significance of family structure may be due to the fact that both parental social control and unstructured socializing were included as covariates, and research suggests that the influence of family structure on delinquency is mediated by factors such as parental control and supervision (Schroeder, Osgood, and Oghia 2010; Voorhis et al. 1988). Furthermore, parental social control might have been non-significant because unstructured socializing was included as a covariate. Unstructured socializing may be the more proximate cause of violence, that is, youths who lack sufficient parental social control may be more likely to engage in unsupervised socializing and therefore have more opportunities to engage in violence.

However, the most important finding in this study is that there is a statistically significant relationship between support for revenge and violence, even after controlling for other known predictors of violence such as victimization, peer delinquency, unstructured socializing, and low 
self-control. Prior research indicates that those who experience victimization are more likely to engage in antisocial behaviors (Jennings et al. 2012). This could be due to one of many factors; for example, those with a propensity for violence may be more likely to participate in activities where they are more likely to be victimized. However, victimization may lead those who were victimized to seek revenge against those who harmed them. Future research should examine whether the influence of victimization on subsequent violence is mediated by support for revenge. Alternatively, in his fullest exposition of general strain theory, Agnew (2006:25) argues that the relationship between strain (e.g., victimization) and antisocial behaviors (e.g., violence) will be conditioned by "beliefs that justify criminal responses." Therefore, future research should investigate whether the relationship between victimization and violence is conditional on the support for revenge.

Of course, the findings regarding self-control and violence are also interesting. While self-control was significantly and positively associated with violence in the model without support for revenge, the relationship was no longer significant when support for revenge was included. This is interesting because the relationship between low self-control and antisocial behaviors such as violence is one of the most robust findings in criminological research (Pratt and Cullen 2000; Vazsonyi et al. 2017). However, it may be the case that specific definitions for violence are a more important, and more proximate cause, of violence than low self-control. For example, those with low self-control may engage in violence and only afterwards adopt beliefs that rationalize or justify their behavioral patterns (Maruna and Copes 2005). Alternatively, those with low self-control may select into peer groups where certain beliefs and behaviors are reinforced by similarly disposed individuals (McGloin and Shermer 2009). 
There are several practical implications of the current study. First, it provides further evidence that beliefs favorable to violent behavior are associated with violence. Beliefs and attitudes regarding crime and delinquency are common risk and protective factors that are targeted by preventive (Farrington and Loeber 1998; Farrington and Welsh 2007) and rehabilitative programming (Andrews and Bonta 2010). To the extent that these programs target beliefs regarding revenge, they should continue doing so; and programs that do not should consider addressing this important risk factor. Reducing youth's support and desire for revenge may not only reduce violence, but promoting forgiveness and reconciliation may have positive social, emotional, and health benefits (Lawler et al. 2005; McCullough 2008).

Unfortunately, although the number of evidence-based interventions has grown in recent decades, there is still a need to develop more effective forms of preventive interventions. For example, many community-based interventions have fared poorly when implemented in areas with multiple, complex social problems such as many inner-city communities (Fagan and Lowe 2019). Given that several bodies of literature suggests that revenge plays a key role in the etiology of violence (Anderson 2000; Nisbett and Cohen 1996) and cycles of violence (Abt 2019; Decker 1996), programs may need to incorporate practices and activities that promote forgiveness and reconciliation. Preventing youth violence may also be a more difficult task than preventing other forms of antisocial behavior, such as substance use, as there are far more evidence-based interventions that are known to reduce substance use than there are that reduce outcomes such as violence (see Blueprints for Healthy Youth Development 2018)

In their systematic meta-review of evaluations of youth violence prevention programs Matjasko et al. (2012) found that treatment-specific prevention programs (cognitive behavioral therapy, multisystemic therapy, and life skills training programs) reported only moderate or weak 
effects on youth violence. Some of the currently used and widely studied manualized interventions for diminishing aggression, such as Aggression Replacement Training include moral reasoning as the cognitive component of the intervention. However, in their review of 16 ART intervention studies, Brännström et al. (2016) concluded that there is an insufficient evidence to show that ART would have a positive impact on moral development, recidivism, self-control or social skills among adolescents. In other words, even when violence prevention programs exist, there is still much room for improving their effectiveness. The preliminary evidence of this study suggests that interventions should increasingly include tools for changing attitudes towards revenge.

Despite the important contributions of this paper, it is not without its limitations; these limitations create additional avenues for future research. For example, one of the greatest limitations of this study is that it utilizes cross-sectional data, which eliminates our ability to make causal statements regarding the relationship between support for revenge and violence. Because the data are cross-sectional, the study cannot establish temporal precedence of support for revenge. While it is possible that support for revenge serves as the basis for subsequent violent behaviors, it is also possible that, after engaging in deviant behaviors, adolescents attempt to save face and maintain their sense of self-worth by rationalizing and/or justifying their behaviors. This is a common criticism of research that examines the relationship between beliefs and behaviors (Akers and Sellers 2012; Maruna and Copes 2005). Longitudinal studies should examine whether support for revenge predicts subsequent violence, while statistically controlling for prior violent behavior. This limitation is particularly important regarding the non-significance of self-control in the full model because it is possible that individuals with low self-control engage in self-serving behaviors and then adopt beliefs that justify those behaviors. Low self- 
control and support for revenge were moderately correlated $(r=.45 ; p<.05)$, which suggests that future longitudinal studies should examine the relationship between victimization, low selfcontrol, and the adoption of beliefs favorable to vengeful behaviors.

However, the fact that the sample is of Finnish adolescents may also play a role in the findings. For example, some research suggests that indicators of low self-control may be less influential predictors of violence among Finnish adolescents (Kivivuori et al. 2012; Kivivuori, Savolainen, and Aaltonen, 2016), although this needs more research. Furthermore, researchers may find different results using samples from other countries, especially samples from the United States. Many cultural theories developed in the United States suggest that socio-structural and socio-historical factors have given rise to cultures that approve of, or at least tolerate, revenge for utilitarian purposes (e.g., using revenge to preserve status and/or deter future violence; see Anderson 2000; Nisbet and Cohen 1996). Given that Finland is a much more homogenous nation (Patsiurko, Campbell, and Hall 2012), with lower levels of economic inequality $(\mathrm{OECD}, 2020)$, and substantially different experience in terms of racial and ethnic relations than the US, many of the factors that theoretically give rise to utilitarian violence in the US may not be as important in Finland. Therefore, support for revenge may be a more prevalent and more influential cause of violence in countries such as the United States.

Given that revenge comes in many forms, studies should also examine whether support for revenge is associated with broader measures of violence as well as other forms of crime and delinquency such as theft, robbery, and vandalism. Finally, additional research should examine the relationship between support for revenge and violence using data from other nations around the world. Given that several theories suggest cultures vary in their support for revenge, it is plausible that the relationship may be stronger in some societies and weaker in others. The 
current study uses data from Finland; future studies should examine the relationship in other Western and non-Western countries. 


\section{References}

Abt, Thomas. 2019. Bleeding Out: The Devastating Consequences of Urban Violence--and a Bold New Plan for Peace in the Streets. Basic Books.

Agnew, Robert. 1994. “The Techniques of Neutralization and Violence.” Criminology 32(4):555-580.

Agnew, Robert. 2006. Pressured into Crime: An Overview of General Strain Theory. Oxford; New York: Oxford University Press.

Agnew, Robert and Sandra Huguley. 1989. “Adolescent Violence toward Parents." Journal of Marriage and the Family 51(3):699-711.

Akers, Ronald L. 1996. "Is Differential Association/Social Learning Cultural Deviance Theory?" Criminology 34(2):229-247.

Akers, Ronald L. 2009. Social Learning and Social Structure a General Theory of Crime and Deviance. New Brunswick: Transaction Publishers.

Akers, Ronald L. and Christine Sharon Sellers. 2012. Criminological Theories: Introduction, Evaluation, and Application. Oxford; New York: Oxford University Press.

Anderson, Elijah. 2000. Code of the Street: Decency, Violence, and the Moral Life of the Inner City. W. W. Norton \& Company.

Andrews, D. A. and James Bonta. 2010. The Psychology of Criminal Conduct. 5th ed. Albany, NY: Lexis Nexis/Anderson Pub.

Asparouhov, Tihomir. 2006. "General Multi-Level Modeling with Sampling Weights." Communications in Statistics - Theory and Methods 35(3):439-60.

Bellair, Paul E., Vincent J. Roscigno, and Maria B. Velez. 2003. "Occupational Structure, Social Learning, and Adolescent Violence" edited by G. Jensen. Social Learning Theory and the Explanation of Crime 11:197-225.

Bernburg, Jón Gunnar and Thorolfur Thorlindsson. 2001. "Routine Activities in Social Context: A Closer Look at the Role of Opportunity in Deviant Behavior." Justice Quarterly 18(3):543-67.

Blueprints for Healthy Youth Development. 2018. "Blueprints for Healthy Youth Development." Programs. Retrieved June 22, 2018 (http://www.blueprintsprograms.com/).

Butts, Jeffrey A., Caterina Gouvis Roman, Lindsay Bostwick, and Jeremy R. Porter. 2015. “Cure Violence: A Public Health Model to Reduce Gun Violence." Annual Review of Public Health 36(1):39-53. 
Cardozo, Barbara Lopes, Alfredo Vergara, Ferid Agani, and Carol A. Gotway. 2000. "Mental Health, Social Functioning, and Attitudes of Kosovar Albanians Following the War in Kosovo." JAMA 284(5):569-77.

Child Trends Databank. 2018. "Physical Fighting by Youth.” Child Trends. Retrieved August 26, 2019 (https://www.childtrends.org/indicators/physical-fighting-by-youth).

Cohen, Dov. 1996. "Law, Social Policy, and Violence: The Impact of Regional Cultures." Journal of Personality and Social Psychology 70(5):961-78.

Cohen, Dov, Richard E. Nisbett, Brian F. Bowdle, and Norbert Schwarz. 1996. "Insult, Aggression, and the Southern Culture of Honor: An 'Experimental Ethnography.'” Journal of Personality and Social Psychology 70(5):945-60.

Cohen, Dov, Joseph Vandello, Sylvia Puente, and Adrian Rantilla. 1999. "When You Call Me That, Smile!' How Norms for Politeness, Interaction Styles, and Aggression Work Together in Southern Culture." Social Psychology Quarterly (3):257.

Copeland-Linder, Nikeea, Sara B. Johnson, Denise L. Haynie, Shang-en Chung, and Tina L. Cheng. 2012. "Retaliatory Attitudes and Violent Behaviors Among Assault-Injured Youth." Journal of Adolescent Health 50(3):215-20.

Copes, Heith. 2003. "Streetlife and the Rewards of Auto Theft." Deviant Behavior 24(4):309-32.

Copes, Heith, Andy Hochstetler, and Craig J. Forsyth. 2013. "Peaceful Warriors: Codes for Violence Among Adult Male Bar Fighters.” Criminology 51(3):761-94.

Costello, Barbara. 1997. "On the Logical Adequacy of Cultural Deviance Theories." Theoretical Criminology 1(4):403-428.

Crombag, Hans, Eric Rassin, and Robert Horselenberg. 2003. "On Vengeance.” Psychology, Crime \& Law 9(4):333-44.

Decker, Scott H. 1996. “Collective and Normative Features of Gang Violence.” Justice Quarterly 13(2):243-64.

Elisha, Ety, Yael Idisis, Uri Timor, and Moshe Addad. 2010. "Typology of Intimate Partner Homicide: Personal, Interpersonal, and Environmental Characteristics of Men Who Murdered Their Female Intimate Partner." International Journal of Offender Therapy and Comparative Criminology 54(4):494-516.

Ellis, Lee, Kevin M. Beaver, and John Wright. 2009. Handbook of Crime Correlates. Academic Press.

European Commission. 2017. "Organisation of Private Education.” Eurydice - European Commission. Retrieved May 26, 2020 (https://eacea.ec.europa.eu/nationalpolicies/eurydice/finland/organisation-private-education_en). 
Fagan, Abigail A. and C. Cory Lowe. 2019. "Mobilizing Communities to Prevent Adolescent Substance Use and Delinquency." in International Handbook of Delinquency and Heath, edited by S. Hupp and J. Jewell. New York: Routledge.

Farrell, Graham, Nick Tilley, and Andromachi Tseloni. 2014. "Why the Crime Drop?" Crime and Justice 43(1):421-90.

Farrington, David P. 1998. "Predictors, Causes, and Correlates of Male Youth Violence." Crime and Justice 24:421-75.

Farrington, David P. and Rolf Loeber. 1998. Serious and Violent Juvenile Offenders: Risk Factors and Successful Interventions. SAGE.

Farrington, David P. and Brandon Welsh. 2007. Saving Children from a Life of Crime: Early Risk Factors and Effective Interventions. Oxford; New York: Oxford University Press.

Felson, Marcus and Mary Eckert. 2015. Crime and Everyday Life. SAGE Publications.

Finnish National Board on Research Integrity. 2019. The Ethical Principles of Research with Human Participants and Ethical Review in the Human Sciences in Finland. Helsinki, Finland: Finnish National Board on Research Integrity.

Garman, Julie D., Lisa L. Sample, and Sarah A. Steele. 2019. "From Playboy to Prison: When Pornography Use Becomes a Crime." Deviant Behavior 1-19.

Gastil, Raymond D. 1971. "Homicide and a Regional Culture of Violence." American Sociological Review 36(3):412.

Gerber, Monica M. and Jonathan Jackson. 2013. "Retribution as Revenge and Retribution as Just Deserts.” Social Justice Research 26(1):61-80.

Gogineni, Rama Rao and April E. Fallon. 2013. "The Ubiquitous Nature of Revenge: Biopsychocultural Perspectives.” Pp. 119-44 in Revenge: Narcissistic Injury, Rage, and Retaliation, edited by S. Akhtar and H. Parens. Lanham, MD: Rowman \& Littlefield.

Gottfredson, Michael and Travis Hirschi. 1987. "The Methodological Adequacy of Longitudinal Research on Crime.” Criminology 25:581-614.

Gottfredson, Michael R. and Travis Hirschi. 1990. A General Theory of Crime. Stanford University Press.

Grasmick, Harold G., Charles R. Tittle, Robert J. Bursik, and Bruce J. Arneklev. 1993. "Testing the Core Empirical Implications of Gottfredson and Hirschi's General Theory of Crime." Journal of Research in Crime and Delinquency 30(1):5-29.

Heck, Ronald H., Scott L. Thomas, and Lynn Naomi Tabata. 2012. Multilevel Modeling of Categorical Outcomes Using IBM SPSS. New York; London: Routledge. 
Heimer, Karen. 1997. "Socioeconomic Status, Subcultural Definitions, and Violent Delinquency." Social Forces 75(3):799.

Hirschi, Travis. 1996. "Theory Without Ideas: Reply to Akers.” Criminology 34(2):249-56.

Jacobs, Bruce A. and Richard Wright. 2006. Street Justice: Retaliation in the Criminal Underworld. Cambridge; New York: Cambridge University Press.

Jennings, Wesley G., Alex R. Piquero, and Jennifer M. Reingle. 2012. "On the Overlap between Victimization and Offending: A Review of the Literature." Aggression and Violent Behavior 17(1):16-26.

Kivivuori, Janne, Pirjo Lindfors, Mikko Aaltonen, Venla Salmi, Lasse Pere, and Arja Rimpelä. 2012. Correlates of Violent Behaviour among Finnish Adolescents Aged 12 to 18: Exploring the Feasibility of a Health Survey in Criminological Analysis. Research Brief. Finland: National Research Institute of Legal Policy.

Kivivuori, Janne, Jukka Savolainen, and Mikko Aaltonen. 2016. "The Revenge Motive in Delinquency: Prevalence and Predictors.” Acta Sociologica 59(1):69-84.

Kornhauser, Ruth Rosner. 1978. Social Sources of Delinquency: An Appraisal of Analytic Models. University of Chicago Press Chicago.

Kubrin, Charis E. and Ronald Weitzer. 2003. "Retaliatory Homicide: Concentrated Disadvantage and Neighborhood Culture." Social Problems 50(2):157-80.

Kurtenbach, Sebastian, Steffen Zdun, Simon Howell, Muhammad Zaman, and Abdul Rauf. 2019. "Global Street Code. A Cross-Cultural Perspective on Youth Violence." Deviant Behavior $1-22$.

Lawler, Kathleen A., Jarred W. Younger, Rachel L. Piferi, Rebecca L. Jobe, Kimberley A. Edmondson, and Warren H. Jones. 2005. "The Unique Effects of Forgiveness on Health: An Exploration of Pathways." Journal of Behavioral Medicine 28(2):157-67.

Lee, Matthew R., William B. Bankston, Timothy C. Hayes, and Shaun A. Thomas. 2007.

"Revisiting the Southern Culture of Violence." The Sociological Quarterly 48(2):253-75.

Lee, Matthew R. and Graham C. Ousey. 2011. "Reconsidering the Culture and Violence Connection: Strategies of Action in the Rural South." Journal of Interpersonal Violence 26(5):899-929.

Lee, Matthew R., Shaun A. Thomas, and Graham C. Ousey. 2009. "Southern Culture and Homicide: Examining the Cracker Culture/Black Rednecks Thesis." Deviant Behavior 31(1):60-96.

Loeber, Rolf. 2012. "Does the Study of the Age-Crime Curve Have a Future." Pp. 11-19 in The Future of Criminology, edited by R. Loeber and B. C. Welsh. New York, NY: Oxford University Press. 
Maimon, David and Christopher R. Browning. 2010. "Unstructured Socializing, Collective Efficacy, and Violent Behavior Among Urban Youth*." Criminology 48(2):443-74.

Maruna, Shadd and Heith Copes. 2005. "What Have We Learned from Five Decades of Neutralization Research?" Crime and Justice 3:221-320.

Matsuda, Kristy N., Chris Melde, Terrance J. Taylor, Adrienne Freng, and Finn-Aage Esbensen. 2013. "Gang Membership and Adherence to the 'Code of the Street."' Justice Quarterly 30(3):440-68.

Matsueda, Ross L. 1997. “Cultural Deviance Theory': The Remarkable Persistence of a Flawed Term.” Theoretical Criminology 1(4):429-452.

McCullough, Michael. 2008. Beyond Revenge: The Evolution of the Forgiveness Instinct. John Wiley \& Sons.

McGloin, Jean Marie, and Lauren O’Neill Shermer. 2009. "Self-Control and Deviant Peer Network Structure." Journal of Research in Crime and Delinquency 46(1):35-72.

Mears, Daniel, Eric A. Stewart, Sonja E. Siennick, and Ronald L. Simons. 2013. "The Code of the Street and Inmate Violence: Investigating the Salience of Imported Belief Systems." Criminology 51(3):695-728.

Näsi, Matti. 2016. Nuorten Rikoskäyttäytyminen Ja Uhrikokemukset 2016. Helsinki, Finland: Kriminologian ja oikeuspolitiikan instituutti.

Nisbett, Richard E. and Dov Cohen. 1996. Culture of Honor: The Psychology of Violence in the South. Boulder, Colo: Westview Press.

Organization for Economic Cooperation and Development. 2020. "Income Inequality." OECD Data. Retrieved May 30, 2020 (http://data.oecd.org/inequality/income-inequality.htm).

Patsiurko, Natalka, John L. Campbell, and John A. Hall. 2012. "Measuring Cultural Diversity: Ethnic, Linguistic and Religious Fractionalization in the OECD." Ethnic and Racial Studies 35(2):195-217.

Pratt, Travis C. and Francis T. Cullen. 2000. "The Empirical Status of Gottfredson and Hirschi's General Theory of Crime: A Meta-Analysis." Criminology 38(3):931-64.

Pratt, Travis C., Francis T. Cullen, Christine S. Sellers, L. Thomas Winfree Jr, Tamara D. Madensen, Leah E. Daigle, Noelle E. Fearn, and Jacinta M. Gau. 2010. "The Empirical Status of Social Learning Theory: A Meta-Analysis.” Justice Quarterly 27(6):765-802.

de Quervain, D. J. F., Urs Fischbacher, Valerie Treyer, Melanie Schellhammer, Ulrich Schnyder, Alfred Buck, and Ernst Fehr. 2004. "The Neural Basis of Altruistic Punishment." Science 305(5688):1254-58. 
Rabe-Hesketh, S. and Anders Skrondal. 2012. Multilevel and Longitudinal Modeling Using Stata. 3rd ed. College Station, Tex: Stata Press Publication.

Rebellon, Cesar j. and Paul Anskat. 2018. "Crime, Deviance, and Social Control: Travis Hirschi and His Legacy." Pp. 189-205 in The Handbook of the History and Philosophy of Criminology, edited by R. A. Triplett. Hoboken, NJ: John Wiley \& Sons.

Schroeder, Ryan D., Aurea K. Osgood, and Michael J. Oghia. 2010. "Family Transitions and Juvenile Delinquency." Sociological Inquiry 80(4):579-604.

Seddig, Daniel. 2014. "Peer Group Association, the Acceptance of Norms and Violent Behaviour: A Longitudinal Analysis of Reciprocal Effects.” European Journal of Criminology 11(3):319-339.

Sellers, Christine S., John K. Cochran, and L. Thomas Winfree Jr. 2003. “Social Learning Theory and Courtship Violence: An Empirical Test" edited by G. Jensen. Social Learning Theory and the Explanation of Crime 11:109-127.

Skardhamar, Torbjørn, Mikko Aaltonen, and Martti Lehti. 2014. "Immigrant Crime in Norway and Finland." Journal of Scandinavian Studies in Criminology and Crime Prevention 15(2):107-27.

Sowell, Thomas. 2006. Black Rednecks and White Liberals. San Francisco, Calif.: Encounter Books.

Stewart, Eric A. and Ronald L. Simons. 2006. "Structure and Culture in African American Adolescent Violence: A Partial Test of the Code of the Street Thesis." Justice Quarterly 23:1-33.

Stewart, Eric A. and Ronald L. Simons. 2010. "Race, Code of the Street, and Violent Delinquency: A Multilevel Investigation of Neighborhood Street Culture and Individual Norms of Violence." Criminology 48(2):569-605.

Sykes, Gresham M. and David Matza. 1957. "Techniques of Neutralization: A Theory of Delinquency.” American Sociological Review 22(6):664-70.

Thornberry, Terence P., Carolyn A. Smith, Craig Rivera, David Huizinga, and Magda Stouthamer-Loeber. 1999. Family Disruption and Delinquency. NCJ-178285. Washington, D.C.: Office of Juvenile Justice and Delinquency Prevention.

Vazsonyi, Alexander T., Jakub Mikuška, and Erin L. Kelley. 2017. "It's Time: A Meta-Analysis on the Self-Control-Deviance Link." Journal of Criminal Justice 48:48-63.

Voorhis, Patricia Van, Francis T. Cullen, Richard A. Mathers, and Connie Chenoweth Garner. 1988. "The Impact of Family Structure and Quality on Delinquency: A Comparative Assessment of Structural and Functional Factors*." Criminology 26(2):235-61. 
Warr, Mark. 2002. Companions in Crime: The Social Aspects of Criminal Conduct. Cambridge, UK ; New York: Cambridge University Press.

Wells, L. Edward and Joseph H. Rankin. 1991. "Families and Delinquency: A Meta-Analysis of the Impact of Broken Homes." Social Problems 38(1):71-93. 
Table 1. Correlations and Descriptive Statistics

\begin{tabular}{|c|c|c|c|c|c|c|c|c|c|c|c|}
\hline Variable & 1. & 2. & 3. & 4. & 5. & 6. & 7. & 8. & 9. & 10. & 11. \\
\hline 1. Revenge & - & & & & & & & & & & \\
\hline 2. Victimization & $.17^{*}$ & - & & & & & & & & & \\
\hline $\begin{array}{l}\text { 3eer } \\
\text { Delinquency }\end{array}$ & $.28^{*}$ & $.31 *$ & - & & & & & & & & \\
\hline $\begin{array}{l}\text { Unstructured } \\
\text { Socializing }\end{array}$ & $.30^{*}$ & $.16^{*}$ & $.49 *$ & - & & & & & & & \\
\hline $\begin{array}{l}\text { Par. Social } \\
\text { Control }\end{array}$ & $-.23 *$ & $-.09 *$ & $-.20^{*}$ & $-.27 *$ & - & & & & & & \\
\hline $\begin{array}{l}\text { Low Self- } \\
\text { Control }\end{array}$ & $.45^{*}$ & $.19 *$ & $.36^{*}$ & $.44^{*}$ & $-.26^{*}$ & - & & & & & \\
\hline 7. Gender & $.25^{*}$ & $.20 *$ & $.14^{*}$ & $.09 *$ & $-.12 *$ & $.12 *$ & - & & & & \\
\hline $\begin{array}{ll}\text { 8. } & \text { Family } \\
\text { Structure }\end{array}$ & $.07 *$ & $.12 *$ & $.13 *$ & $.10^{*}$ & $-.14 *$ & $.10 *$ & -.02 & - & & & \\
\hline $\begin{array}{l}\text { Immigrant } \\
\text { Background }\end{array}$ & .02 & .02 & .02 & -.02 & .00 & $.03 *$ & $.04 *$ & $.06^{*}$ & - & & \\
\hline 10. Age & .02 & $.05 *$ & .02 & $.04 *$ & $-.05 *$ & $.03 *$ & $.04 *$ & $.04 *$ & $.13 *$ & - & \\
\hline $\begin{array}{l}\text { Past-year } \\
\text { 11. Violence }\end{array}$ & $.22^{*}$ & $.27 *$ & $.30^{*}$ & $.26^{*}$ & $-.13^{*}$ & $.21 *$ & $.12 *$ & $.07 *$ & $.05^{*}$ & $.04 *$ & - \\
\hline Mean & 2.64 & .29 & 1.67 & 2.20 & 3.85 & 2.06 & .49 & .35 & .12 & 15.27 & .08 \\
\hline SD & .85 & .45 & .68 & .89 & .76 & .57 & .50 & .48 & .33 & .47 & .27 \\
\hline Range & $1-5$ & $0-1$ & $1-3$ & $1-5$ & $1-5$ & $1-4$ & $0-1$ & $0-1$ & $0-1$ & $15-17$ & $0-1$ \\
\hline
\end{tabular}


Table 2. Multilevel Logistic Regression Models Predicting Physical Violence

\begin{tabular}{|c|c|c|c|c|c|c|}
\hline \multirow[b]{2}{*}{ Variable } & \multicolumn{3}{|c|}{ Model $1(n=5891)$} & \multicolumn{3}{|c|}{ Model $2(n=5823)$} \\
\hline & OR & $\beta$ & $R S E(\beta)$ & OR & $\beta$ & $R S E(\beta)$ \\
\hline Revenge Attitudes & - & - & - & $1.64 * * *$ & .50 & .10 \\
\hline Victimization & $4.13 * * *$ & 1.42 & .13 & $3.94 * * *$ & 1.37 & .14 \\
\hline Peer Delinquency & $2.22 * * *$ & .80 & .12 & $2.17 * * *$ & .78 & .12 \\
\hline Unstructured Socializing & $1.63 * * *$ & .49 & .08 & $1.60 * * *$ & .47 & .08 \\
\hline Parent Social Control & .88 & -.13 & .09 & .91 & -.10 & .09 \\
\hline Low Self-Control & $1.57 * *$ & .45 & .15 & 1.26 & .23 & .16 \\
\hline Gender & $1.86^{* * *}$ & .62 & .13 & $1.69 * * *$ & .52 & .14 \\
\hline Family Structure & 1.02 & .02 & .14 & 1.01 & .01 & .14 \\
\hline Immigrant & $2.15 * * *$ & .77 & .20 & $2.11 * * *$ & .75 & .20 \\
\hline \multicolumn{7}{|l|}{ Age $(15=$ reference $)$} \\
\hline 16 & 1.18 & .16 & .14 & 1.22 & .20 & .15 \\
\hline 17 & .67 & -.41 & .61 & .23 & -1.49 & .86 \\
\hline Constant & $.00 * * *$ & -7.01 & .54 & $.00 * * *$ & -7.94 & .57 \\
\hline Variance (Intercept) & \multicolumn{3}{|c|}{.085} & \multicolumn{3}{|c|}{.079} \\
\hline $\mathrm{ICC}$ & \multicolumn{3}{|c|}{.025} & \multicolumn{3}{|c|}{.023} \\
\hline \multicolumn{7}{|l|}{ Model Fit } \\
\hline $\mathrm{AIC}$ & \multicolumn{3}{|c|}{2492.31} & \multicolumn{3}{|c|}{2382.84} \\
\hline $\mathrm{BIC}$ & \multicolumn{3}{|c|}{2572.49} & \multicolumn{3}{|c|}{2469.54} \\
\hline Log-Likelihood & \multicolumn{3}{|c|}{-1234.16} & \multicolumn{3}{|c|}{-1178.42} \\
\hline
\end{tabular}

Note: ${ }^{*} p<.05 ;{ }^{*} p<.01 ; * * * p<.001 ; R S E=$ robust standard errors 